\title{
ATITUDES FACE À HOMOSSEXUALIDADE: UMA PROPOSTA DE AVALIAÇÃO PARA A INTERVENÇÃO SOCIOEDUCATIVA
}

\author{
Cristiana Pereira Carvalho ${ }^{1}$ \\ Maria do Rosário Moura Pinheiro ${ }^{2}$ \\ Daniela Lopes Martins ${ }^{3}$ \\ Ana Filipa Simões ${ }^{4}$ \\ Maria de Jesus Maceiras ${ }^{5}$
}

\begin{abstract}
RESUMO O preconceito e a discriminação baseada na orientação homossexual ainda persistem nos ambientes sociais, escolares e acadêmicos, pelo que a educação e a formação nessas áreas se justifica. Para intervir é então necessário identificar as atitudes em relação à homossexualidade, o que por sua vez exige que haja instrumentos de avaliação confiáveis. Nesse sentido, os estudos apresentados tiveram como finalidade construir e validar a versão portuguesa da Escala de Atitudes face à Homossexualidade - Versão para estudantes do ensino superior. Participaram 108 estudantes, de ambos os gêneros, da Licenciatura em Ciências da Educação da Universidade de Coimbra. Os resultados da análise da dimensionalidade da escala revelaram uma estrutura tridimensional, composta por três fatores: Atitudes não discriminatórias face à homossexualidade (F1), Atitudes de defesa dos direitos dos homossexuais $(\mathrm{F} 2)$ e Atitudes de rejeição à proximidade de pessoas homossexuais $(\mathrm{F} 3)$. A partir de testes estatísticos foi possível identificar diferenças nas atitudes face à homossexualidade em função do gênero, da religião, do contato e da proximidade com amigos/as gays ou lésbicas. Verificou-se, ainda, que as atitudes positivas face à homossexualidade aumentam à medida que aumentam os conhecimentos e crenças funcionais sobre a homossexualidade. Os resultados sugerem que esta escala pode ser útil no diagnóstico de atitudes homofóbicas e na avaliação de intervenções de prevenção da homofobia e de promoção da igualdade, respeito, aceitação e valorização da diversidade no que diz respeito à orientação sexual. São apresentadas e discutidas implicações e sugestões para futuros estudos e intervenções socioeducativas.
\end{abstract}

Palavras-chave: Homofobia. Gênero. Atitudes.

\footnotetext{
${ }^{1}$ Mestre em Ciências da Educação pela Faculdade de Psicologia e de Ciências da Educação da Universidade de Coimbra (FPCE-UC). Doutoranda em Ciências da Educação, na área de especialização em Psicologia da Educação (FPCEUC / Centro de Investigação do Núcleo de Estudos e Intervenção Cognitivo-Comportamental CINEICC / Bolseira FCT).

${ }^{2}$ Licenciada em Psicologia e Doutora em Ciências da Educação pela FPCE-UC". em Ciências da Educação pela FPCE-UC. Professora Auxiliar na Faculdade de Psicologia e de Ciências da Educação da Universidade de Coimbra (FPCE-UC). Membro colaborador do CINEICC e docente responsável pelo Gabinete de Apoio ao Estudante - GAE/FPCE-UC.

${ }^{3}$ Mestre em Ciências da Educação pela Faculdade de Psicologia e de Ciências da Educação da Universidade de Coimbra (FPCE-UC).

${ }^{4}$ Mestre em Ciências da Educação pela Faculdade de Psicologia e de Ciências da Educação da Universidade de Coimbra (FPCE-UC).

${ }^{5}$ Doutora em Psicologia pela Universidade da Extremadura. Prof ${ }^{a}$ Adjunta na Escola Superior de Saúde da Cruz Vermelha Portuguesa - ESSCVP (Lisboa).
} 


\title{
ATTITUDES TOWARD HOMOSEXUALITY: AN EVALUATION PROPOSAL TO A SOCIOEDUCATIONAL INTERVENTION
}

\begin{abstract}
Prejudice and discrimination based on homosexual orientation still persist in social, school and academic situations. So education and training in these areas is justified. In order to intervene, it is necessary to identify attitudes towards homosexuality, which in turn requires reliable assessment instruments. In this sense, the studies presented had the purpose of constructing and validating the Portuguese version of the Attitudes Scale toward Homosexuality - Version for students of higher education for the Portuguese population. Participants included 108 students of both genders, students of the Degree in Educational Sciences of the University of Coimbra. The results of the dimensionality analysis of the scale, based on 24 items, revealed a three-dimensional structure, composed by three factors: Non-discriminatory attitudes towards homosexuality (F1), Attitudes of defence of the rights of homosexuals (F2) and Attitudes of rejection in the proximity of homosexual people (F3). From statistical tests it was possible to identify differences in attitudes about homosexuality according to gender, religion, contact and proximity to gay or lesbian friends. It was also found that positive attitudes towards homosexuality increase as knowledge and functional beliefs about homosexuality increase. The results suggest that this scale can be useful in the diagnosis of homophobic attitudes and in the evaluation of interventions that prevent homophobia and promote equality, respect, acceptance and appreciation of diversity with regard to sexual orientation. Implications and suggestions for future studies and socioeducational interventions are presented and discussed.
\end{abstract}

Key-words: Homophobia. Gender. Attitudes.

\section{INTRODUÇÃO}

Em Portugal, nos últimos 20 anos tem emergido um conjunto de evoluções legais referentes aos direitos civis $^{6}$ das minorias sexuais (COSTA, PEREIRA, OLIVEIRA \& NOGUEIRA, 2010). No entanto, o preconceito, a discriminação, a exclusão e a estigmatização em função da orientação sexual parecem persistir nos diferentes espaços sociais (COMISSÃO EUROPEIA, 2009; NOGUEIRA \& OLIVEIRA, 2010; REDE EX AEQUO, 2014), com implicações negativas na saúde e bem-estar desta população (ALBUQUERQUE \& WILLIAMS, 2015; REDE EX AEQUO, 2014). Apesar das diversas legislações, desenvolvidas a nível nacional e internacional no âmbito da Declaração Universal dos Diretos Humanos, que condenam todas as formas de discriminação (GATO, FONTAINE, LEME \& LEME, 2015), estudos recentes continuam a disponibilizar dados que confirmam a existência de preconceito subtil e simbólico (COSTA et al, 2010; CASTILLO et al, 2003; BOURDIEU,

\footnotetext{
${ }^{6}$ Aprovação da união de facto/estável em 2001, inclusão na Constituição Portuguesa da orientação sexual nos princípios da igualdade (artigo 13) em 2004, casamento entre pessoas do mesmo sexo em 2010 e aprovação da lei da co-adoção em 2013.
} 


\section{ITTMERARUUS REFLECTIONIS}

Volume,13, número 2, ano, 2017

1998) contra pessoas não heterossexuais e cuja expressão de gênero não se enquadre nos modelos hegemónicos de masculinidade e feminilidade (COSTA et al, 2010; PEREIRA, MONTEIRO \& CAMINO, 2009).

A este respeito, alguns autores têm salientado a possível existência de variáveis preditoras do preconceito sexual e da homofobia ${ }^{7}$ (COSTA et al, 2010; TESTOR, 2010), pelo fato de aparecerem sistematicamente associadas a atitudes negativas por parte das pessoas heterossexuais em relação às pessoas homossexuais (gays e lésbicas), das quais se destacam: (1) serem do sexo masculino (GATO \& FONTAINE, 2011; COSTA et al, 2010), (2) terem baixos níveis de escolaridade e serem mais velhas (HEREK, 1991; SIMON, 1998; COSTA et al, 2010), (3) terem atitudes mais conservadoras face aos papéis de gênero (GATO \& FONTAINE, 2011), (4) serem mais religiosas e possuírem uma moral mais conservadora (HEREK, 1991; 1994), (5) terem pouco ou nenhum contato pessoal com pessoas homossexuais (GATO \& FONTAINE, 2011; COSTA et al, 2010; HEREK, 1991) e (6) apresentarem um posicionamento político de direita (COSTA et al, 2010). Por outro lado, a existência de conhecimentos elevados sobre a homossexualidade (ALDERSON et al, 2009) e um maior contato interpessoal e de proximidade com gays e lésbicas (GATO \& FONTAINE, 2011; COSTA et al, 2010) parecem estar fortemente associados a atitudes mais positivas e menos homofóbicas (ALDERSON et al, 2009).

No âmbito dos comportamentos homofóbicos, que abrangem crenças negativas especificamente dirigidas às mulheres lésbicas e aos homens gays (COSTA et al, 2010; ALDERSON et al, 2009) e atitudes negativas e desfavoráveis para com os indivíduos devido à orientação sexual (GATO, FONTAINE \& LEME, 2014; HEREK, 2009), algumas pesquisas têm sugerido que as motivações que desencadeiam o preconceito sexual dizem respeito não tanto às identidades gays e lésbicas, mas à sua manifestação explícita e à visibilidade destas identidades, "principalmente quando questionam a normatividade da heterossexualidade nos espaços públicos” (GATO, FONTAINE \& CAMEIRO, 2012, p. 13).

Entre os efeitos da discriminação baseados na orientação sexual, que se traduzem em situações que podem ir de "simples piadas" (violência simbólica e subtil) até ao insulto direito

\footnotetext{
${ }^{7} \mathrm{O}$ constructo homofobia tem sido criticado por alguns autores (MORRISON \& MORRISON, 2002; HEREK, 2000), na medida em que considera as reações contra as pessoas homossexuais como uma fobia (HEREK, 1994) e um medo incontrolável (CARNEIRO, 2009), quando na verdade este se carateriza mais pela hostilidade, pelas atitudes negativas relativamente às pessoas não heterossexuais e pelo sistema de crenças de gênero (KITE \& DEAUX, 1987) que dificulta a aceitação da diversidade sexual (CARNEIRO, 2009). Apesar desta importante distinção, optámos por utilizar tanto o termo homofobia como de preconceito sexual quando nos referirmos à discriminação baseada na orientação sexual (GATO, FONTAINE \& LEME, 2014).
} 


\section{ITINERARIUS REFLECTIONIS}

Volume,13, número 2, ano, 2017

e agressão física (bullying homofóbico) (REDE EX AEQUO, 2014) que ocorrem em espaços públicos (como as escolas) e privados (como a família), os estudos destacam: a depressão (RUSSELL, 2011), os transtornos de estresse pós-traumático (RIVERS, 2004), a ideação suicida e/ou tentativa de suicídio (RUSSELL, 2011; BONTEMPO \& D’AUGELLI, 2002), os transtornos alimentares (RIVERS, 2004), o consumo de substâncias psicoativas (RUSSELL, 2011), os baixos níveis de autoestima (KOSCIW et al, 2012), o abandono escolar e a baixa ligação à escola (KOSCIW et al, 2012), entre outros. Estes sintomas e problemas psicossociais impactam nos níveis de satisfação de vida na idade adulta (TOOMEY et al, 2010) e influenciam negativamente o bem-estar e a saúde mental desta população (RUSSELL et al, 2011; ALBURQUERQUE \& WILLIAMS, 2015; REDE EX AEQUO, 2014).

Para a concretização de uma educação para a cidadania, assente em princípios de igualdade e respeito, que condene todas as situações de discriminação, de veiculação de informação incorreta, preconceituosa e contrária aos direitos humanos das pessoas homossexuais (REDE EX AEQUO, 2014), as escolas devem, não só desenvolver ações educativas sobre o tema da orientação sexual e da identidade de gênero, como previsto na lei que regulamenta a implementação da educação sexual nas escolas portuguesas (artigo $3^{\circ}$ da Portaria nº196-A/2010 para o $2^{\circ}$ ciclo do ensino básico - conteúdo Diversidade e Respeito) (PORTARIA Nº196-A/2010), mas também afirmar-se como espaços de segurança para os/as jovens gays e lésbicas (REDE EX AEQUO, 2014; UNESCO, 2016).

Considerando o papel educativo e de socialização que a escola desempenha na vida das crianças e jovens, assim como os diversos desafios que encontra para lidar com a diversidade (UNESCO, 2016), compete à equipe escolar, composta por professores/as e funcionários/as, romper com os estereótipos e preconceitos ainda fomentados na sociedade em geral (SOUZA et al, 2016). Uma prática pedagógica baseada em valores de igualdade, cidadania e respeito pela diversidade e pelo outro, implica a capacitação e sensibilização dos/as professores/as-coordenadores/as da educação para a saúde e educação sexual e de todos/as os/as docentes que integram estas equipes interdisciplinares nas escolas (LEI N. ${ }^{\circ} 60 / 2009 ;$ PORTARIA N. ${ }^{\circ} 196-A / 2010$ ), para que possam estar preparados/as e sensibilizados/as para a problemática da homofobia em meio escolar (ALBURQUERQUE \& WILLIAMS, 2015; REDE EX AEQUO, 2014).

Os estudantes do ensino superior, enquanto futuros profissionais e agentes educativos, têm sido alvo de diversas pesquisas relativamente às atitudes face à homossexualidade 


\section{ITHNERARHUS \\ REFLECTIONIS}

REVISTA ELETRÔNICA

DA GRADUAÇÃO/PÓS-GRADUAÇÃO EM EDUCAÇÃ O

ISSN. 1807-9342

Volume,13, número 2, ano, 2017

(GATO, FONTAINE \& LEME, 2014; CARDEIRA, MÓNICO \& CASTRO, 2014; GATO, FONTAINE \& CARNEIRO, 2012; GATO \& FONTAINE, 2011; CERQUEIRA-SANTOS et al, 2007; LACERDA, PEREIRA, \& CAMINO, 2002), cujos resultados podem auxiliar na elaboração de propostas curriculares e extra-curriculares de formação inicial e contínua, e ainda de propostas de intervenção socioeducativas, particularmente importantes entre os cursos de formação de professores/as, das ciências da educação, da psicologia e do serviço social.

Nesta linha de pensando, este estudo teve como objetivo desenvolver uma escala de atitudes face à homossexualidade especificamente para estudantes do ensino superior (para os quais não existe nenhuma medida relacionada com os hábitos e rotinas que fazem parte da vida acadêmica) e analisar as suas caraterísticas psicométricas. Nesse sentido, este estudo preliminar realizado com estudantes da Licenciatura em Ciências da Educação (futuros Pedagogos) procurou verificar a existência de diferenças relativas ao género, à religião, ao contacto com amigos/as homossexuais e analisar uma possível relação com as crenças sobre a homossexualidade. Através dos resultados obtidos são apresentadas implicações e propostas para a intervenção socioeducativa.

\section{Metodologia}

\subsection{Participantes}

A amostra do estudo é constituída por 108 estudantes do ensino superior, dos quais $15 \%(n=16)$ são rapazes e $85 \%(n=91)$ são raparigas $^{8}$, com uma média de idades de 21 anos ( $M=21.30, D P=2.62$; mínimo de 19 e máximo de 35 anos). A maioria dos/as estudantes são portugueses/as $(91.6 \%, n=98)$, consideram-se religiosos/as $(71.7 \%, n=76)$ (predominando a Religião Católica) e cursavam a Licenciatura em Ciências da Educação. Dos/as estudantes participantes, $60.2 \%$ frequentavam o $2^{\circ}$ ano do curso $(\mathrm{M}=2.34, \mathrm{DP}=.53), 37 \%(\mathrm{n}=40)$ o $3^{\circ}$ ano e apenas $2.8 \%(n=3)$ dos/as alunos/as o $1^{\circ}$ ano. Relativamente à orientação sexual, $98.1 \%$ $(n=105)$ considera-se heterossexual e $1.9 \%(n=2)$ bissexual. A maioria dos/as estudantes tem um amigo homossexual (gay ou lésbica) $(63.6 \%, n=68)$.

\section{Estudo 1 - Análise Fatorial Exploratória}

\subsection{Instrumento}

\footnotetext{
${ }^{8}$ Termo utilizado em Portugal para designar moças.
} 


\section{ITHERARHUS REFLECTIONIS}

Volume,13, número 2, ano, 2017
REVISTAELETRÔNICA

DA GRADUAÇÃ O/PÓS - GRADUAÇÃO EM EDUCAÇÃ O

ISSN. 1807-9342

\section{Escala de Atitudes face à Homossexualidade - Versão para estudantes do ensino} superior

A Escala de Atitudes face à Homossexualidade - Versão para estudantes do ensino superior (EAH-EES) foi desenvolvida a partir de uma revisão da literatura (elaborada em 2013 por Carvalho, Simões e Pinheiro), a qual apresenta indicadores referentes ao preconceito sexual, como a rejeição à proximidade, as manifestações (des)favoráveis aos direitos sexuais e mais subtis de discriminação. Para a elaboração dos itens consultamos diversas escalas de atitudes sobre a homossexualidade, como Escala Multidimensional de Atitudes Face a Lésbicas e a Gays (GATO, FONTAINE \& CARNEIRO, 2012), Modern Homophobia Scale (RAJA \& STOKES, 1998), The Homophobia Scale (WRIGHT, ADAMS \& BERNAT, 1999) e Index of Homophobia (HUDSON \& RICKETTS, 1980).

Uma vez que desconhecemos a existência de medidas psicométricas disponíveis na literatura sobre as atitudes negativas ou positivas dos/as estudantes do ensino superior em relação à orientação sexual dos/as colegas e que traduzam aspetos da vida acadêmica ${ }^{9}$ relativamente ao convívio e contacto com estudantes gays e lésbicas, optámos pela construção de itens que representem as rotinas e hábitos dos/as estudantes do ensino superior (i.e., Faria um trabalho de grupo com um colega gay ou lésbica; Votaria num candidato homossexual nas eleições para o núcleo de estudantes da minha faculdadeluniversidade; Sentir-me-ia desconfortável se tivesse que falar com um professor sabendo que ele é homossexual; Não me sentaria na aula próximo de uma pessoa gay ou lésbica).

No processo de construção e aperfeiçoamento da escala, esta foi submetida à apreciação de dois júris com conhecimento na área, que avaliaram a pertinência e adequação dos itens. Posteriormente, realizamos um estudo piloto com estudantes da Faculdade de Psicologia e de Ciências da Educação da Universidade de Coimbra, dos cursos de Psicologia e de Ciências da Educação, que analisaram o grau de facilidade/dificuldade em relação à compreensão das instruções e dos respetivos itens. Após esta análise e recolhidos os diversos contributos e sugestões dos dois especialistas na área e dos/as estudantes, as alterações efetuadas deram origem à versão final do questionário.

Desta forma, esta escala é um instrumento de autorresposta, composto por um conjunto de 37 itens, cuja escala de resposta de Likert de cinco pontos (1-Discordo totalmente

\footnotetext{
9 Como por exemplo "fazer um trabalho de grupo", "sair à noite ou ir a um convívio acadêmico", "pedir apontamentos das aulas", "sentar ao lado de um/a colega na aula", "dividir casa ou viver numa residência universitária".
} 


\section{ITINERARHS REFLECTIONIS}

Volume,13, número 2, ano, 2017

ISSN. 1807-9342

a 5-Concordo totalmente) permite identificar as atitudes face à homossexualidade por parte dos/as estudantes do ensino superior. A escala é constituída por itens positivos (i.e., Participaria numa manifestação sobre os direitos das pessoas gays e lésbicas) e negativos (i.e., Eu não pediria apontamentos das aulas a um(a) colega que fosse gay ou lésbica). Optámos pela não inversão dos itens para facilitar a leitura dos mesmos. É de esperar que pontuações mais elevadas indiquem atitudes mais positivas e/ou negativas consoante a direção dos itens.

\section{2 Procedimentos}

A amostra foi recolhida na Faculdade de Psicologia e de Ciências da Educação da Universidade de Coimbra/Portugal, particularmente nas turmas do curso de Ciências da Educação. Todos/as os/as participantes foram esclarecidos/as sobre a natureza e o propósito do estudo, assim como foi assegurada a confidencialidade e o anonimato das respostas. Os/as estudantes deram o seu consentimento livre e esclarecido e participaram voluntariamente no preenchimento do protocolo de investigação (composto por este e outros instrumentos) na sala de aula, na presença de um dos elementos desta equipe. O tempo aproximado de preenchimento do questionário foi de 15 minutos. A recolha de dados decorreu entre Setembro e Outubro de 2013.

\subsection{Análise de dados}

A EAH-EES foi submetida a uma análise fatorial exploratória pelo método de componentes principais (ACP), com rotação Varimax, por se tratar de uma escala construída por nós, sem histórico de utilizações anteriores e, consequentemente, sem conhecimento da sua consistência interna e fidelidade na avaliação das atitudes dos estudantes universitários em relação aos sujeitos homossexuais (gays e lésbicas). Foram extraídos os fatores comuns com um valor próprio superior a 1, em consonância com o Scree Plot e a percentagem de variância retida (MARÔCO, 2007). Os índices de Kaiser-Meyer-Olkin (KMO) e de Bartlett's Test of Sphericity foram tidos em consideração. A consistência interna foi analisada através do Coeficiente alfa de Cronbach. A análise estatística dos dados realizou-se com recurso ao 


\section{ITHERARHUS REFLECTIONIS}

Volume,13, número 2, ano, 2017
REVISTA ELETRÔNICA

DA GRADUAÇÃO/PÓS-GRADUAÇÃO EM EDUCAÇÃ O

ISSN. 1807-9342

programa SPSS (Statistical Package for Social Sciences, versão 20 para Windows, Chicago, IL, USA).

\subsection{Resultados}

Os 37 itens da EAH-EES foram submetidos a uma análise fatorial livre, tendo-se verificado um conjunto de 4 fatores com valores próprios (eigen values) superiores a 1, que explicam $48.36 \%$ da variância total, em que alguns itens apresentam valores de saturação fatorial elevados em mais do que um fator e apenas dois itens em algumas dimensões. Nesta primeira análise obteve-se na medida de Kaiser-Meyer-Olkin (KMO) o valor de .843.

Neste sentido, novas análises foram testadas, a fim de obtermos a que se apresentava interpretável considerando o conteúdo de cada um dos itens e a sua importância na medição do constructo em causa. Desta forma, a análise em ACP, com rotação varimax, forçada a 3 fatores foi a que se relevou mais apropriada. Os itens 5 ("Se soubesse da existência de um caloiro gay ou lésbica iria praxá-lo de forma mais cuidadosa") $\left(\mathrm{h}^{2}=.163\right), 10$ ("Seria capaz de defender uma pessoa que estivesse a ser alvo de algum tipo de discriminação devido à sua orientação sexual”) ( $\left.\mathrm{h}^{2}=.288\right), 17$ ("Se eu descobrisse que o/a meu/minha melhor amigo/a é gay ou lésbica isso mudaria muita coisa") ( $\left.\mathrm{h}^{2}=.289\right), 31$ ("Penso que deveria haver residências universitárias para gays ou lésbicas") $\left(\mathrm{h}^{2}=.287\right), 32$ (“Concordo que haja bares/associações só para gays e lésbicas") $\left(\mathrm{h}^{2}=.294\right), 33$ ("Acho que os estudantes estrangeiros assumem mais a sua homossexualidade") ( $\left.\mathrm{h}^{2}=.279\right), 34$ ("Quando conheço alguém de novo procuro saber se é gay ou lésbica") ( $\left.\mathrm{h}^{2}=.256\right), 35$ ("Não gostaria de participar numa Parada Gay, pois tinha medo de ser confundido/a com eles") ( $\left.\mathrm{h}^{2}=.297\right)$ e 37 ("Se fosse pai ou mãe poderia aceitar que o meu filho ou a minha filha fosse homossexual") $\left(\mathrm{h}^{2}=.286\right)$ apresentaram comunalidades pouco satisfatórias e saturações inferiores a .30, razão pela qual optamos pela sua eliminação. Embora o item 9 ("Seria capaz de defender os direitos das pessoas gays e lésbicas num grupo de amigos"), 15 (“Seria capaz de entrar num bar gay"), 23 ("Não apresentaria um amigo gay ao/à me/minha namorado/a") e 27 ("Não viveria numa residência universitária com pessoas gays ou lésbicas") não apresentem problemas de comunalidade, optámos pela sua eliminação, uma vez que saturavam em mais do que um fator e com isso a consistência interna das subescalas aumentou significativamente.

Desta forma, optámos pela estrutura composta por três fatores, integrando 24 itens que explicam $50.4 \%$ da variância total (Tabela 1), na qual obteve-se na medida de adequação da 


\section{ITHERARHUS REFLECTIONIS}

Volume,13, número 2, ano, 2017

REVISTA ELETRÔNICA

DA GRADUAÇÃO/PÓS-GRADUAÇÃO EM EDUCAÇÃ O

ISSN. 1807-9342

amostragem de Kaiser um KMO de .795 e de Bartlett's Test of Sphericity significativo $\left[\chi^{2}(276)=1314.218, \mathrm{p}<.001\right]$. O primeiro fator, que apresenta um valor próprio de $7.76 \mathrm{e}$ explica $32.3 \%$ da variância (Tabela 1), foi denominado por Atitudes não discriminatórias face à homossexualidade (domínio pessoal e privado) (F1) e é composto por 9 itens $(3,4,14,21$, 22, 24, 25, 26 e 28) que refletem atitudes favoráveis à convivência diária com pessoas gays e/ou lésbicas. O segundo fator foi denominado por Atitudes de defesa dos direitos dos homossexuais (domínio social e público) (F2) por integrar 8 itens (1, 2, 11, 12, 13, 18, 19 e 29) que expressam a defesa pela existência de espaços (na própria Universidade) de apoio e informação sobre a homossexualidade e a participação de movimentos em defesa dos direitos sociais das pessoas LGBT. Apresenta um valor próprio de 2.51 e explica $10.4 \%$ da variância. O terceiro fator apresenta um valor próprio de 1.84 e explica $7.7 \%$ da variância (Tabela 1) e foi denominado por Atitudes de rejeição à proximidade de pessoas homossexuais (homofobia) (F3), por contemplar 7 itens $(6,7,8,16,20,30$ e 36) que abordam a rejeição ao contato com pessoas homossexuais e ao desconforto em conviver com elas. A consistência interna das subescalas do instrumento revelaram índices de alpha de Cronbach que variam entre .76 e .90 (Tabela 1).

Tabela 1. Análise em componentes principais da EAH-EES / Método de rotação: Varimax com normalização de Kaiser

\begin{tabular}{|c|c|c|c|c|c|c|}
\hline \multirow[b]{2}{*}{ Itens } & \multicolumn{3}{|c|}{ Fator } & \multirow[b]{2}{*}{$h^{2}$} & \multirow{2}{*}{$\begin{array}{l}\text { Média } \\
\text { (DP) }\end{array}$} & \multirow{2}{*}{$\begin{array}{l}\mathbf{r} \\
\text { item total } \\
\text { corrigido }\end{array}$} \\
\hline & 1 & 2 & 3 & & & \\
\hline $\begin{array}{l}\text { 3. Iria beber café ou sair à noite com um/a amigo/a } \\
\text { gay ou lésbica. }\end{array}$ & .844 & .149 & -.017 & .73 & $4.54(.63)$ & .678 \\
\hline $\begin{array}{l}\text { 4. Faria um trabalho de grupo com um colega gay } \\
\text { ou lésbica. }\end{array}$ & .743 & .076 & -.003 & .56 & $4.62(.54)$ & .541 \\
\hline $\begin{array}{l}\text { 25. Convidava um/a amigo/a gay ou lésbica para } \\
\text { fazer uma viagem. }\end{array}$ & .730 & .295 & -.333 & .73 & $4.05(.81)$ & .820 \\
\hline $\begin{array}{l}\text { 14. Iria a um convívio académico sabendo que } \\
\text { também iriam lá estar muitas pessoas gays ou } \\
\text { lésbicas. }\end{array}$ & .700 & -.012 & -.233 & .54 & $4.28(.82)$ & .625 \\
\hline $\begin{array}{l}\text { 21. Eu convidaria um/a amigo/a homossexual para } \\
\text { ir jantar a minha casa. }\end{array}$ & .685 & .123 & -.255 & .55 & $4.19(.91)$ & .665 \\
\hline $\begin{array}{l}\text { 26. Apresentaria uma amiga lésbica ao/à } \\
\text { meu/minha namorado/a. }\end{array}$ & .633 & .149 & -.405 & .59 & $4.13(.88)$ & .714 \\
\hline $\begin{array}{l}\text { 28. Partilharia o quarto com um/a colega gay ou } \\
\text { lésbica. }\end{array}$ & .594 & .292 & -.312 & .54 & 3.47 (1.13) & .667 \\
\hline
\end{tabular}




\section{ITHNERARHUS REFLECTIONIS}

Volume,13, número 2, ano, 2017

REVISTA ELETRÔNICA

DA GRADUAÇÃ O/PÓS - GRADUAÇÃ O EM EDUCAÇÃ O

ISSN. 1807-9342

22. Eu apresentaria aos meus pais um/a amigo/a homossexual.

24. Votaria num candidato homossexual nas eleições para o núcleo de estudantes da minha faculdade/universidade.

12. Gostaria que existisse na minha faculdade um espaço de esclarecimento em relação às questões da orientação sexual e dos direitos sexuais das pessoas gays ou lésbicas.

1. Gostaria de falar com uma pessoa gay ou lésbica sobre questões da homossexualidade.

11. Gostaria de ver discutido, numa disciplina, um vídeo que falasse sobre as questões da orientação sexual.

19. Eu gostaria de fazer parte de um grupo de jovens que promovesse intervenções contra a violência face aos homossexuais.

29. Participaria numa manifestação sobre os direitos das pessoas gays e lésbicas.

13. Deveria existir na minha faculdade um espaço de apoio psicológico para as questões da orientação sexual.

2. Falaria no meu grupo de amigos sobre as questões da homossexualidade.

18. Eu gostaria de assinar uma petição a favor da adoção por casais do mesmo sexo.

30.Se soubesse da existência de um colega homossexual no meu grupo desportivo (ex: futebol, ginásio...) mudava de equipa/local.

6. Não me sentaria na aula próximo de uma pessoa gay ou lésbica.

20. Eu não pediria apontamentos das aulas a um/a colega que fosse gay ou lésbica.

36. Sentir-me-ia pouco à vontade se descobrisse que o meu médico ou a minha médica não era heterossexual.

7. Sentir-me-ia desconfortável se tivesse que falar com um professor sabendo que ele é homossexual.

16. Sentir-me-ia desconfortável ao ver um casal homossexual a beijar-se.

8. Gostaria de assinar uma petição a favor dos direitos sexuais das pessoas gays e lésbicas.
.593

$\begin{array}{lllll}.301 & -.242 & .47 & 4.22 & (.79)\end{array}$

.631

.573

$\begin{array}{llll}.128 & -.439 & .54 & 4.05 \\ (.86)\end{array}$

.671

.105

$\begin{array}{llll}.728 & .100 & .55 & 3.53 \\ (.79)\end{array}$

.557

.309

$\begin{array}{llll}.720 & .120 & .63 & 3.56 \\ (1.04)\end{array}$

.638

.101

$\begin{array}{lllll}.710 & -.044 & .52 & 3.89 & (.86)\end{array}$

.564

.009

$\begin{array}{lllll}.672 & -.250 & .52 & 3.50 & (.96)\end{array}$

.566

.124

$\begin{array}{lllll}.605 & -.433 & .57 & 3.20 & (.98)\end{array}$

.574

$\begin{array}{lllll}.042 & \mathbf{. 5 6 2} & -.074 & .32 & 3.70\end{array}(.83)$

.405

.244

$\begin{array}{lllll}.482 & -.249 & .35 & 3.29 & (1.18)\end{array}$

$\begin{array}{llllll}-.115 & .032 & .766 & .61 & 1.44(.82) & .566\end{array}$

$\begin{array}{lllll}-.077 & -.050 & .711 & .51 & 1.35\end{array}(.78)$

$\begin{array}{lllll}-.145 & .010 & \mathbf{6 0 7} & .39 & 1.44(.91)\end{array}$

$\begin{array}{llllll}-.283 & -.011 & \mathbf{5 6 5} & .40 & 1.75 & (.94)\end{array}$

$\begin{array}{llllll}-.114 & -.147 & \mathbf{5 1 8} & .30 & 1.41 & (.74)\end{array}$

$\begin{array}{lllllll}-.326 & -.173 & .456 & .34 & 2.69(1.10) & .440\end{array}$

$\begin{array}{lllllll}-.220 & -.333 & .413 & .33 & 3.61(1.04) & .326\end{array}$ $\begin{array}{lllll}.454 & \mathbf{. 5 3 3} & .044 & .49 & 4.28 \\ (.85)\end{array}$ 
Volume,13, número 2, ano, 2017

ISSN. 1807-9342

\begin{tabular}{lccc} 
Valor próprio & 7.76 & 2.51 & 1.84 \\
Variância explicada & $32.3 \%$ & $10.4 \%$ & $7.7 \%$ \\
Variância total & \multicolumn{4}{c}{$\mathbf{5 0 . 4 \%}$} \\
Alfa de Cronbach & .90 & .82 & .76 \\
\hline
\end{tabular}

Fonte: Autores, 2017

Considerando que o item 8 "Gostaria de assinar uma petição a favor dos direitos sexuais das pessoas gays e lésbicas" apresentou valores de saturação negativos (-.413) na dimensão 3 (Tabela 1), procedemos à inversão do item (razão pela qual agora apresenta um valor positivo). Por esta razão, este item deve ser interpretado como "Não gostaria de assinar uma petição a favor dos direitos sexuais das pessoas gays e lésbicas”. Propomos que em futuras utilizações deste instrumento, este item seja alterado como sugerido anteriormente para facilitar a leitura e compreensão do mesmo.

4 Estudo 2 - Diferenças de género, religião, amizade com pessoas homossexuais, comunicação com pais, amigos e abordagem do tema na Universidade

\subsection{Instrumentos}

Para a realização da análise de diferenças foram utilizadas perguntas de natureza pessoal, como o género (Masculino e Feminino), a religião (Consideras-te religioso: "sim” ou "não") e ter algum/a amigo/a gay ou lésbica ("sim" ou "não") que fizeram parte dos dados sociodemográficos. Optámos também por analisar algumas das questões da última parte do protocolo de investigação relacionadas com a comunicação na família sobre a orientação sexual ("Gostava que os meus pais tivessem falado mais comigo sobre o tema da orientação sexual"), a abordagem da temática na Faculdade ("Gostava de ver debatido o tema da orientação sexual na minha Faculdade"), o desejo de ter mais conhecimento ("Gostava de ter mais informação sobre o tema da orientação sexual") e a comunicação com os/as amigos/as ("Falo com os meus amigos/as sobre o tema da orientação sexual"), respondidas de acordo com uma escala dicotómica de "sim" ou "não".

\subsection{Análise de dados}

Para a análise dos dados foram utilizadas estatísticas descritivas e inferenciais, por meio do programa SPSS versão 20 (SPSS Inc, Chicago, IL). Foram verificados os pressupostos para o cálculo de estatística inferencial paramétrica, nomeadamente a distribuição das variáveis e a homocedasticidade. Não existiram pontuações outliers na 


\section{ITHNERARHS REFLECTIONIS}

Volume,13, número 2, ano, 2017
REVISTA ELETRÔNICA

DA GRADUAÇÃO/PÓS-GRADUAÇÃO EM EDUCAÇÃO

ISSN. 1807-9342

amostra em estudo (HAIR, ANDERSON \& TATHAM, 1995). Considerando a dimensão da amostra aplica-se o Teorema do Limite Central (ou teorema de Lindberg-Levy) que afirma que para amostras grandes a distribuição tende para a normalidade (MURTEIRA, RIBEIRO, SILVA \& PIMENTA, 2001; DURRETT, 2010). A decisão foi reforçada pela análise dos histogramas, e por essa razão, optou-se por utilizar testes paramétricos (teste $t$ student). A homocedasticidade foi testada através do teste de Levene (HOWELL, 2013). Apesar de existir homogeneidade das variâncias, optamos pela prova robusta Brown-Forsythe, por existirem diferenças relevantes no tamanho dos grupos a comparar (TABACHNICK, \& FIDELL, 2007).

\subsection{Resultados}

Para compreender melhor os resultados das dimensões da Escala de Atitudes face à Homossexualidade na presente amostra de estudantes universitários, cruzaram-se variáveis de natureza pessoal dos/as jovens, como o género, a religião e ter algum/a amigo/a gay ou lésbica. Relativamente ao género, as raparigas $(M=29.64, D P=4.13, n=91)$ apresentam médias mais elevadas do que os rapazes $(M=26.32, D P=5.89, n=16)$ na dimensão Atitudes de defesa dos direitos dos homossexuais (domínio social e público) $(\mathrm{F} 2)[\mathrm{t}(17.678)=-2.163 ; \mathrm{p}=.045]$. Os/as estudantes que referem não ter religião $(M=10.70, D P=2.89, n=30)$ quando comparados com os que se dizem religiosos/as $(M=13.17, D P=4.27, n=76)$ apresentam médias mais baixas na dimensão Atitudes de rejeição à proximidade de pessoas homossexuais (homofobia) (F3) $[\mathrm{t}(78.003)=3.428 ; \mathrm{p}=.001]$.

Por outro lado, ter um/a amigo/a homossexual revelou diferenças significativas em todas as dimensões da escala. Os/as estudantes que têm amigos/as gays ou lésbicas $(M=38.72$, $D P=5.04$ (F1) e $M=29.96, D P=4.51$ (F2), $n=68$ respetivamente) apresentam médias mais elevadas do que os que não têm amigos/as homossexuais $(M=35.89, D P=5.48$ (F1) e $M=27.26, D P=5.31(\mathrm{~F} 2), n=39$ respetivamente) nas dimensões Atitudes não discriminatórias face à homossexualidade (domínio pessoal e privado) $(\mathrm{F} 1)[\mathrm{t}(105)=2.715 ; \mathrm{p}=.008]$ e Atitudes de defesa dos direitos dos homossexuais (domínio social e público) (F2) [t(105)=2.784; $\mathrm{p}=.006]$. Também se verificou que os/as estudantes que não têm um/a amigo/a gay ou lésbica $(M=13.64, D P=3.62, n=39)$ quando comparados com os que têm amigos/as $(M=11.60$, $D P=3.79, n=68)$ apresentam diferenças estatisticamente significativas na dimensão Atitudes de rejeição à proximidade de pessoas homossexuais (homofobia) (F3) $[\mathrm{t}(105)=-2.724$; $\mathrm{p}=.008$ ], com valores mais elevados. 


\section{ITHNERARIUS REFLECTIONIS}

Volume,13, número 2, ano, 2017
REVISTA ELETRÔNICA

DA GRADUAÇÃ O/PÓS-GRADUAÇÃO EM EDUCAÇÃ O

ISSN. 1807-9342

Os/as estudantes que gostavam que os pais tivessem falado mais sobre a orientação sexual $(M=39.29, D P=5.22$ e $M=31.76, D P=3.46, n=34$ respetivamente $)$, quando comparados/as com os que não gostariam que esse diálogo tivesse ocorrido com maior frequência $(M=36.75, D P=5.52$ e $M=27.65, D P=5.04, n=74$ respetivamente) apresentam médias mais elevadas nas dimensões Atitudes não discriminatórias face à homossexualidade (domínio pessoal e privado) $(\mathrm{F} 1)[\mathrm{t}(106)=2.260 ; \mathrm{p}=.026]$ e Atitudes de defesa dos direitos dos homossexuais (domínio social e público) $(\mathrm{F} 2)[\mathrm{t}(106)=4.305 ; \mathrm{p}=.001]$. Tanto os/as estudantes que gostariam de ver debatido o tema da orientação sexual na Faculdade $(M=28.85, D P=4.28$, $n=88)$, como os/as que gostariam de obter mais informação sobre a temática $(M=30.14$, $D P=4.13, n=62)$ apresentam diferenças estatisticamente significativas $[\mathrm{t}(105)=4.488 ; \mathrm{p}=.001$ e t(105)=3.077; $\mathrm{p}=.003$ respetivamente], com valores mais elevados na dimensão Atitudes de defesa dos direitos dos homossexuais (domínio social e público) (F2) do que os/as jovens que responderam negativamente a estas duas questões $(M=24.63, D P=5.87, n=19$ e $M=27.25$, $D P=5.60, n=45$ respetivamente)

Os/as estudantes que falam com os/as amigos/as sobre a orientação sexual ( $M=38.21$, $D P=5.29, n=89(\mathrm{~F} 1)$ e $M=29.63, D P=4.68, n=89(\mathrm{~F} 2)$ respetivamente), quando comparados com os jovens que não conversam sobre esta temática $(M=34.11, D P=5.69, n=18(\mathrm{~F} 1) \mathrm{e}$ $M=25.28, D P=4.91, n=18(\mathrm{~F} 2)$ respetivamente), apresentam médias mais elevadas nas dimensões Atitudes não discriminatórias face à homossexualidade (domínio pessoal e privado) $(\mathrm{F} 1)[\mathrm{t}(105)=2.963 ; \mathrm{p}=.004]$ e Atitudes de defesa dos direitos dos homossexuais (domínio social e público) $(\mathrm{F} 2)[\mathrm{t}(105)=3.565 ; \mathrm{p}=.001]$ e médias mais baixas $(M=13.61$, $D P=3.78, n=18$ ) na dimensão Atitudes de rejeição à proximidade de pessoas homossexuais (homofobia) (F3) [t(105)=-2.028; $\mathrm{p}=.045]$, quando comparados com os/as que não conversam com os pares $(M=11.50, D P=4.06, n=89)$.

\section{Estudo 3 - Correlações entre as dimensões da Escala de Atitudes face à}

\section{Homossexualidade com o Inventário de Crenças sobre a Homossexualidade}

\subsection{Instrumento}

\section{Inventário de Crenças sobre a Homossexualidade}

O Inventário de Crenças sobre a Homossexualidade (elaborado em 2013 por Carvalho, Simões e Pinheiro) é um instrumento de auto-resposta, composto por 39 itens, que mede a existência de crenças funcionais (i.e., "Os homossexuais podem ser pais", "Os 


\section{ITHNERARHS REFLECTIONIS}

Volume,13, número 2, ano, 2017

homossexuais devem ter os mesmos direitos que os heterossexuais", "De acordo com a Associação Americana de Psiquiatria (APA) (Diagnostic and Statistical Manual of Mental Disorders - DSM) a homossexualidade não é uma doença”) vs disfuncionais sobre a homossexualidade (i.e., "É possível mudar de orientação sexual (um/a homem/mulher homossexual pode mudar para heterossexual)", "A homossexualidade é um desvio ao que é normal e natural", "A homossexualidade resulta da ausência da figura parental do mesmo sexo"). A escala de resposta dicotómica de verdadeiro/falso permite a cotação de um (1) para respostas que se aproximam das crenças funcionais e zero (0) para respostas associadas às crenças disfuncionais. Um (1) significa que a resposta é dada no sentido das crenças funcionais sobre a homossexualidade. Itens não respondidos são cotados como zero (0). Todos os itens devem ser invertidos, à excepção dos itens $5,7,10,14,18,26$ e 38, e o resultado consiste no somatório das respostas. As pontuações mais elevadas refletem crenças funcionais sobre a homossexualidade e os resultados variam entre 0 e 39.

\subsection{Análise de dados}

Para as análises de correlação utilizou-se o coeficiente de correlação de Pearson (HOWELL, 2013) uma vez que as subescalas do instrumento apresentam distribuição normal.

\subsection{Resultados}

Ter crenças funcionais sobre a homossexualidade mostrou-se associado com todas as dimensões da Escala de atitudes face à homossexualidade. As associações são positivas, indicando que quanto mais crenças funcionais os/as estudantes possuem, mais positivas são também as suas atitudes face à homossexualidade $(\mathrm{F} 1)(\mathrm{r}=.513, \mathrm{p}=.001)$ e em prol da defesa dos direitos dos homossexuais $(\mathrm{F} 2)(\mathrm{r}=.246, \mathrm{p}=.001)$. Por outro lado, quando as crenças funcionais aumentam, as atitudes de rejeição à proximidade de pessoas homossexuais (F3) tendem a diminuir $(\mathrm{r}=-.514, \mathrm{p}=.001)$, como se pode verificar pela correlação moderada e positiva entre ambas (Tabela 2).

Os resultados evidenciam que possuir atitudes positivas e não discriminatórias face à homossexualidade (F1) correlaciona-se de forma positiva e significativa com as atitudes de defesa dos direitos dos homossexuais $(\mathrm{F} 2)(\mathrm{r}=.505, \mathrm{p}=.001)$ e negativamente com as atitudes de rejeição às pessoas homossexuais $(\mathrm{F} 3)(\mathrm{r}=-.583, \mathrm{p}=.001)$. Entre os resultados importa ainda salientar que os sujeitos que tendem a ter atitudes de rejeição às pessoas homossexuais (F3) 


\section{ITINERARIUS \\ REFLECTIONIS}

Volume,13, número 2, ano, 2017

DA GRADUAÇÃO/PÓS - GRADUAÇÃO EM EDUCAÇÃ O

ISSN. 1807-9342

(Tabela 2).

Tabela 2. Matriz de correlações de Pearson entre as dimensões da Escala de Atitudes face à Homossexualidade e o Inventário de Crenças sobre a Homossexualidade

\begin{tabular}{|c|c|c|c|c|}
\hline Dimensões dos instrumentos & 1 & 2 & 3 & 4 \\
\hline 1 - Crenças funcionais sobre a homossexualidade & 1 & & & \\
\hline 2 - Atitudes não discriminatórias (F1) & $.513 * *$ & 1 & & \\
\hline 3 - Atitudes de defesa de direitos (F2) & $.246^{* *}$ & $.505 * *$ & 1 & \\
\hline 4 - Atitudes de rejeição à proximidade $(\mathrm{F} 3)$ & $-.514 * *$ & $-.583 * *$ & $-.372 * *$ & 1 \\
\hline
\end{tabular}

\section{Considerações finais}

$\mathrm{O}$ estudo das propriedades psicométricas da Escala de Atitudes face à Homossexualidade - Versão para estudantes do ensino superior (EAH-EES), desenvolvida para conhecer as atitudes dos estudantes para com a homossexualidade, revelou, na versão final composta por 24 itens, uma estrutura fatorial de três fatores, denominados por Atitudes não discriminatórias face à homossexualidade (F1), Atitudes de defesa dos direitos dos homossexuais (F2) e Atitudes de rejeição à proximidade de pessoas homossexuais (F3). A escala apresenta boas caraterísticas psicométricas com uma estrutura tri-dimensional a explicar $50.4 \%$ da variância total e com indicadores de boa consistência interna.

Tal como esperado, os resultados encontrados relativamente às atitudes de defesa pelos direitos dos homossexuais por partes do gênero feminino, às atitudes de maior rejeição à proximidade de pessoas homossexuais pelos/as estudantes que se consideram religiosos/as e às atitudes menos discriminatórias e preconceituosas por parte dos/as estudantes que têm um/a amigo/a gay ou lésbica ou que falam com os/as amigos/as sobre o tema da orientação sexual, corroboram com os achados dos estudos que referem a existência de diferenças em função do género, religião e proximidade com homens gays e mulheres lésbicas, relativamente ao preconceito sexual e à homofobia (GATO \& FONTAINE, 2011; COSTA et al, 2010; HEREK, 1991; 1994). 


\section{ITINERARIUS \\ REFLECTIONIS}

REVISTA ELETRÔNICA

DA GRADUAÇÃO/PÓS-GRADUAÇÃO EM EDUCAÇÃ O

ISSN. 1807-9342

\section{Volume,13, número 2, ano, 2017}

Por outro lado, os/as estudantes mais interessados em ver o tema da orientação sexual debatido na Faculdade, assim como, os que gostariam de obter mais informação sobre a temática e desejariam que os pais tivessem conversado mais sobre a orientação sexual foram os/as que apresentaram atitudes mais positivas e menos discriminatórias face à homossexualidade, tanto no domínio pessoal/privado como no domínio social/público. A este respeito importa destacar a necessidade de criar espaços de diálogo, discussão/esclarecimento e apoio sobre as questões da homossexualidade no Ensino Superior. Igualmente relevante são as ações de educação sexual dirigidas a pais/mães sobre a temática da orientação sexual (UNESCO, 2016), de modo a contribuir para uma comunicação positiva, aberta e calorosa entre pais/mães e filhos/as (VILAR, 2003; DIAS, MATOS \& GONÇALVES, 2007; VILELAS, 2009; CARVALHO \& PINHEIRO, 2013).

Neste sentido, torna-se ainda mais importante a abordagem da temática de forma transversal e contínua desde o ensino básico ${ }^{10}$ (LEI N. ${ }^{\circ}$ 60/2009; PORTARIA N. ${ }^{\circ}$ 196-A/2010) até ao ensino superior, de forma a alcançar o maior número de estudantes, inclusive os alunos do gênero masculino e os que apresentam adesão a crenças disfuncionais, preconceituosas e discriminatórias, ainda responsáveis por perpetuar julgamentos e ações contra as pessoas que não correspondem aos estereótipos de homem/mulher ou ao que julgam ser o caráter normativo da heterossexualidade (COSTA et al, 2010).

O fato de termos encontrado, no presente estudo, associações positivas entre as crenças funcionais sobre a homossexualidade e as atitudes não discriminatórias e de defesa dos direitos das pessoas homossexuais e, por outro, associações negativas com as atitudes de rejeição à proximidade e contato com pessoas não heterossexuais, leva-nos a equacionar que o aumento dos conhecimentos sobre a homossexualidade, a desconstrução de mitos e o desenvolvimento de crenças mais favoráveis, realistas e flexíveis sobre os papéis de género (COSTA et al, 2010) e a orientação sexual possam vir a contribuir favoravelmente para atitudes e comportamentos mais positivos e menos homofóbicos (ALDERSON et al, 2009) e, por isso, social e relacionalmente mais funcionais e saudáveis.

Importa apontar como limitação deste estudo o fato de a amostra ter um nível de formação escolar superior à da população geral, pois encontra-se num contexto universitário, e ser maioritariamente feminina, condições que podem ajudar a compreender as elevadas médias nas atitudes não discriminatórias e nas de defesa dos direitos das pessoas

\footnotetext{
${ }^{10}$ O Ensino Básico em Portugal corresponderia ao Ensino Fundamental no Brasil.
} 


\section{ITINERARHS \\ REFLECTIONIS}

REVISTA ELETRÔNICA

DA GRADUAÇÃO/PÓS-GRADUAÇÃO EM EDUCAÇÃ O

ISSN. 1807-9342

Volume,13, número 2, ano, 2017

homossexuais e, também, as baixas atitudes de rejeição à proximidade de pessoas homossexuais (GATO \& FONTAINE, 2011; COSTA et al, 2010; HEREK, 1991; 1994). Nesse sentido, futuros estudos requerem amostras maiores e mais representativas da diversidade de sexo biológico, identidade de gênero, expressão de gênero e orientação sexual. Importa realçar o fato de à nossa amostra ter sido solicitada informação sobre a sua orientação sexual, sendo este também um aspeto inovador do nosso estudo. Resultou, assim, que a nossa amostra carateriza atitudes face à homossexualidade, de estudantes que se definem como heterossexuais.

Ainda no que diz respeito a futuras pesquisas com recurso a esta escala, sugerimos que sejam ultrapassadas algumas limitações presentes no nosso estudo, que implicarão a realização de outras análises de validade do instrumento, nomeadamente estudos que permitam confirmar a sua estrutura fatorial (análise fatorial confirmatória) e de validade discriminante e concorrente, aplicando outros instrumento construídos, adaptados e validados para o contexto português. Por outro lado, sugerimos a ampliação deste estudo a novas análises em função de fatores que demonstram estar associados à discriminação sexual e à homofobia, como por exemplo a idade, as crenças referentes aos papéis de gênero, o grau de religiosidade, de participação política, o contato interpessoal com gays e lésbicas separadamente (CERQUEIRA-SANTOS et al, 2007). Para além disso, importa ainda analisar cuidadosamente as manifestações de preconceito contemporâneo menos explícito e mais subtil (COSTA et al, 2010; CASTILLO et al, 2003), assim como, analisar as atitudes dos/as estudantes, enquanto futuros/as profissionais, relativamente ao casamento e adoção por pessoas do mesmo sexo (CARDEIRA, MÓNICO \& CASTRO, 2015) e relativas à visibilidade ou expressão da identidade lésbica e gay (HEREK, 2007). Adaptações transculturais a países de língua portuguesa poderiam dar grandes contributos à ciência e à educação, assim como, poderia ser desejável a complexificação da escala de forma a distinguir separadamente as atitudes para com as mulheres lésbicas e os homens gays.

Considerando os resultados obtidos no nosso estudo, tona-se necessário refletir sobre algumas implicações e propostas para a realização de intervenções socioeducativas efetivas de combate à discriminação baseada no género e na orientação sexual no setor educacional que, a nosso ver, passam por: (1) desenvolver ações em meio escolar e acadêmico baseadas em direitos humanos, que promovam uma cultura de paz e que garantam uma educação inclusiva, num ambiente seguro e não violento e, que sejam promotoras de igualdade de 


\section{ITTMERARUIS REFLECTIONIS}

Volume,13, número 2, ano, 2017
REVISTA ELETRÔNICA

DA GRADUAÇÃ O/PÓS-GRADUAÇÃO EM EDUCAÇÃ O

ISSN. 1807-9342

género (tal como previsto nos Objetivos de Desenvolvimento Sustentável); (2) incluir nos currículos de formação inicial de professores/as, das ciências da educação, da psicologia e de outros cursos das ciências sociais uma disciplina sobre sexualidade, género e diversidade sexual, que informe, sensibilize e capacite estes futuros profissionais a estarem atentos/as a todas as formas de discriminação e a denunciarem situações de violência; (3) apoiar a realização de ações de formação contínua para professores/as que os auxilie no planejamento, implementação e avaliação de intervenções preventivas em matéria de violência e discriminação; (4) reforçar a importância dos Gabinetes de Apoio ao Aluno das escolas portuguesas, de ensino obrigatório e de ensino superior, serem apoiados por entidades parceiras especializadas nesta área; (5) desenvolver ações específicas dirigidas aos homens de modo a promover a reflexão sobre os efeitos da homofobia; (6) realizar campanhas públicas e recorrer aos meios de comunicação para sensibilizar e erradicar todas as formas de discriminação nos domínios sociais, culturais, educacionais e políticos; (7) construir materiais didáticos que incluam mensagens positivas sobre a orientação sexual, a identidade e expressão de gênero, assim como, oferecer currículos relevantes nesta área através da educação sexual nas escolas; (8) garantir suporte e apoio efetivo em escolas e outras instituições educativas a alunos/as (do ensino básico ao ensino superior) e às famílias. Desenvolver ações de formação parental para pais sobre estas temáticas, (9) fortalecer as políticas educativas escolares a nível nacional baseadas em evidência sobre como prevenir e abordar a violência relacionada à homofóbia e transfóbia e (10) apoiar as escolas em termos de monitorização e avaliação dos seus programas (UNESCO, 2016; COSTA et al, 2010; REDE EX AEQUO, 2009; 2014).

Embora este estudo tenha um caráter exploratório, dadas as boas qualidades psicométricas da Escala de Atitudes face à Homossexualidade desenvolvida para estudantes universitários, consideramos que esta medida pode ser utilizada no diagnóstico e avaliação de intervenções e programas socioeducativos implementados nas Universidades, cujas adaptações para a sua aplicação aos estudantes do ensino secundário possibilitariam alargar a sua utilização aos programas de educação sexual das escolas portuguesas.

\section{Referências bibliográficas}

ALBUQUERQUE, P.; WILLIAMS, L. Homofobia na Escola: Relatos de Universitários sobre as Piores Experiências. Temas em Psicologia, v. 23, n. 3, p. 663-676. 2015. 
Volume,13, número 2, ano, 2017

ALDERSON, K. G. et.al. Alberta high school counsellors knowledge of homosexuality and their attitudes toward gay males. Canadian journal of Education, Alberta, v. 32, n.1, p. 87-117, 2009.

BONTEMPO, D. E.; D'AUGELLI, A. R. Effects of at-school victimization and sexual orientation on lesbian, gay, or bisexual youths' health risk behavior. Journal of Adolescent Health, n. 30, 364-374. doi: 10.1016/S1054-139X(01)00415-3. 2002.

BOURDIEU, P. A dominação masculina. Oeiras: Celta. 1998.

CARDEIRA, H.; MÓNICO, L.; CASTRO, P. Atitudes dos estudantes universitários portugueses face à adoção de crianças por homossexuais. Enciclopédia Biosfera, 11(20), p. 201-211. 2015.

CARNEIRO, N. S. Homossexualidades: Uma psicologia entre ser, pertencer e participar. Porto: Livpsic. 2009.

CARVALHO, C.; PINHEIRO, M. P. Educação familiar e comunicação sobre sexualidade: as necessidades de (in)formação de pais e filhos. Livro de atas do VIII Simpósio Nacional de Investigação em Psicologia. Associação Portuguesa de Psicologia. p. 138147. 2013

CASTILLO, M. N. Q.; RODRÍGUEZ, V. B.; TORRES, R. R.; PÉREZ, A. R.; MARTEL, E. C. La medida de homofobia manifiesta y sutil. Psicothema, 15(2), p. 197-204. 2003.

CERQUEIRA-SANTOS, E.; WINTER, F.; SALLES, L.; LONGO, J.; TEODORO, M. Contato Interpessoal e Crenças sobre Homossexualidade: Desenvolvimento de uma Escala. Interação em Psicologia, 11(2), p. 221-229. 2007.

COMISSÃO EUROPEIA. Discriminação na EU 2009. 2009.

COSTA, C. G.; PEREIRA, M.; OLIVEIRA, J. M.; NOGUEIRA, C. Imagens sociais das pessoas LGBT. p. 93-147. In: NOGUEIRA, C., OLIVEIRA, J., M. (Orgs.), Estudo sobre a discriminação em função da orientação sexual e da identidade de género. Lisboa: Comissão para a Cidadania e Igualdade de Género. 2010.

DIAS, S.; MATOS, M. G.; GONCALVES, A. Percepção dos adolescentes acerca da influência dos pais e pares nos seus comportamentos sexuais. Analise Psicológica, 4 (XXV): p. 625-634. 2007.

DURRETT, R. Probability: theory and examples (4th Ed) (Cambridge Series in Statistical and Probabilistic Mathematics). Cambridge University Press: Cambridge. 2010.

GATO, J.; FONTAINE, A.; CARNEIRO, N. Escala Multidimensional de Atitudes face a Lésbicas e a Gays: Construção e Validação Preliminar. Paidéia, v. 22, 51, p. 11-20. 2012. 
Volume,13, número 2, ano, 2017

GATO, J., FONTAINE, A. M. \& LEME, V. B. R. Validação e Adaptação Transcultural da Escala Multidimensional de Atitudes Face a Lésbicas e a Gays. Psicologia Reflexão e Crítica, 27(2), p. 257-271. 2014.

GATO, J.; FONTAINE, A.; LEME, V.; LEME, A. Homofobia Transatlântica: Preconceito contra Lésbicas e Gays em Portugal e no Brasil. Temas em Psicologia. v. 23, nº 3, p. 701-713. 2015.

GATO, J.; FONTAINE, A. M. Factores associados ao preconceito homossexual numa amostra de estudantes universitários portugueses: A influência do sexo, do contacto interpessoal com lésbicas e gays, dos valores sociais e das atitudes de género. In: S. NEVES (Coord.), Género e ciências sociais. Maia: ISMAI. 2011.

HAIR, J., ANDERSON, R. E., \& TATHAM, R. L. Multivariate data: Analysis with readings. New Jersey: Prentice-Hall. 1995.

HEREK, G. M. Stigma, prejudice, and violence against lesbians and gay men. In: GONSIOREK, J. C.; WEINRICH, J. D. Homosexuality: Research implications for public policy. Newbury Park: Sage Publications. p. 60-80. 1991.

HEREK, G. M. Assessing heterosexual's attitudes toward lesbians and gay men: A rewiew of empirical research with the ATLG scale. In: GREENE B.; HEREK, G. M. Lesbian and gay psychology: Theory, research, and clinical applications. London: SAGE Publications, Inc., v.1, p. 206-228. 1994.

HEREK, G. M. Sexual prejudice. In: NELSON, T. Handbook of prejudice, stereotyping, and discrimination. New York: Psychology Press. p. 439-465. 2009.

HEREK, G. M. Confronting sexual stigma and prejudice: Theory and practice. Journal of Social Issues, 63(4), p. 905-925. 2007.

HEREK, G. M. The psychology of sexual prejudice. Current directions in psychological science. New York: Wiley Periodicals. v. 9. n. 1. 2000.

HOWELL, D. Statistical methods for psychology (8nd Ed.). Duxbury: Pacific Grove. 2013.

HUDSON, W. W.; RICKETTS, W. A. A strategy for the measurement of homophobia. Journal of Homosexuality, 5(4), 357-372. 1980.

KITE, M. E.; DEAUX, K. Gender belief systems: Homosexuality and implicit inversion theory. Psychology of Women Quarterly, v. 11, p. 83-96. 1987.

KOSCIW, J. G.; GREYTAK, E. A.; BARTKIEWICZ, M. J.; BOESEN, M. J.; PALMER, N. A. The 2011 National School Climate Survey: The experiences of lesbian, gay, bisexual and transgender youth in our nation's schools. New York: Gay, Lesbian \& Straight Education Network. 2012. 
Volume,13, número 2, ano, 2017

LACERDA, M.; PEREIRA, C.; CAMINO, L. Um estudo sobre as formas de preconceito contra homossexuais na perspectiva das representações sociais. Psicologia: Reflexão e Crítica, 15(1), p. 165-178. 2002.

MARÔCO, J. Análise Estatística com Utilização do SPSS. (3a ed). Lisboa, Portugal: Edições Silabo. 2007.

MINISTÉRIO DA EDUCAÇÃO E DA SAÚDE. (2010). Portaria n. ${ }^{\circ}$ 196-A/2010. Diário da Republica. N. ${ }^{\circ} 69$ - 1.a serie de 9 de Abril de 2010

MINISTÉRIO DA EDUCAÇÃO. (2009). Lei n. ${ }^{\mathbf{6}}$ 60/2009. D.R. $\mathrm{N}^{\mathrm{o}} 151-$ 1. $^{\mathrm{a}}$ série de 6 de Agosto de 2009.

MORRISON, M. A.; MORRISON, T. G. Development and validation of a scale measuring modern prejudice toward gay men and lesbian women. Journal of Homosexuality, 43(2), p. 15-37. 2002.

MURTEIRA, B.; RIBEIRO, C.; SILVA, J.; PIMENTA, C. Introdução à estatística. Lisboa: Mc Graw-Hill. 2001.

NOGUEIRA, C.; OLIVEIRA, J. M. Um olhar da psicologia feminista crítica sobre os direitos humanos de pessoas GLBT. In Nogueira C.; Oliveira, J. M., Estudo sobre a discriminação em função da orientação sexual e da identidade de género. Comissão para a Cidadania e a Igualdade de Género. Lisboa. Portugal. p. 9-17. 2010.

PEREIRA, A.; MONTEIRO, M. B.; CAMINO, L. Social norms and prejudice against homosexuals. The Spanish Journal of Psychology, 12(2), 576-584. (2009).

RAJA, S.; STOKES, J. P. Assessing attitudes toward lesbians and gay men: The Modern Homophobia Scale. Journal of Gay, Lesbian, and Bisexual Identity, 3(2), p.113-134. 1998.

RIVERS, I. Recollections of bullying at school and their long-term implications for lesbians, gay men, and bisexuals. Crisis, 25(4), p.169-175. 2004.

RUSSELL, S. T. Challenging homophobia in schools: Policies and programs for safe school climates. Educar em Revista, 39, p. 123-138. 2011.

RUSSELL, S. T.; RYAN, C.; TOOMEY, R. B.; DIAZ, R. M.; SANCHEZ, J. Lesbian, gay, bisexual and transgender adolescent school victimization: Implications for young adult health and adjustment. Journal of School Health, 81(5), p. 223-230. 2011.

REDE EX AEQUO. Educar para a Diversidade: Um Guia para Professores sobre Orientação Sexual e Identidade de Género. Projeto Educação LGBT. $2^{a}$ Edição. Lisboa: Rede Ex аеquo. 2009.

REDE EX AEQUO. Observatório de Educação LGBT 2014. Lisboa: Rede ex aequo. 2014. 


\section{ITINERARIUS REFLECTIONIS}

REVISTA ELETRÔNICA

DA GRADUAÇÃO/PÓS-GRADUAÇÃO EM EDUCAÇÃ O

Volume,13, número 2, ano, 2017

ISSN. 1807-9342

SIMON, A. The relationship between stereotypes of and attitudes toward lesbians and gay. In Herek, G. M., Stigma and sexual orientation: Understanding prejudice against lesbian, gay men, and bisexuals. London: SAGE Publications, Inc. p. 62-81. 1998.

SOUZA, A., et al. A Ideologia do Movimento Escola Sem Partido: 20 autores desmontam o discurso. São Paulo: Editora Ação Educativa. 2016.

TABACHNICK, B.; FIDELL, L. Using multivariate analysis (5th Ed.). Needham Heights, MA: Allyn \& Bacon. 2007.

TESTOR, C. P. et al. Teachers' attitudes and beliefs about homosexuality. The Spanish Journal of Psychology, Madrid, v.13, n.1, p.138-155, 2010.

TOOMEY, R. B.; RYAN, C.; DIAZ, R. M.; CARD, N. A.; RUSSEL, S. T. Gendernonconforming lesbian, gay, bisexual, and transgender youth: School victimization and young adult psychosocial adjustment. Developmental Psychology, 46(6), p. 15801589. 2010.

UNESCO. Out in the open: Education sector responses violence based on sexual orientation and gender identity/expression. Paris: UNESCO. 2016.

VILAR, D. Falar Disso: A Educação Sexual nas Famílias dos Adolescentes. Porto: Edições Afrontamento. 2003.

VILELAS, J. A Influencia da Família e da Escola na Sexualidade do Adolescente. Coimbra: Editora Formasau. 2009.

WRIGHT, L. W.; ADAMS, H. E.; BERNAT, J. Development and validation of the Homophobia Scale. Journal of Psychopathology and Behavioral Assessment, 21(4), 337-347. 1999. 